\title{
ADAPTACIÓN DEL GESTOR DE COLECCIONES DIGITALES CONTENTDM EN UN ENTORNO CORPORATIVO
}

\author{
Yolanda De-la-Iglesia-Sánchez, Pilar Uguina-Cocostegüe y José-Manuel \\ Fuertes-Conde
}

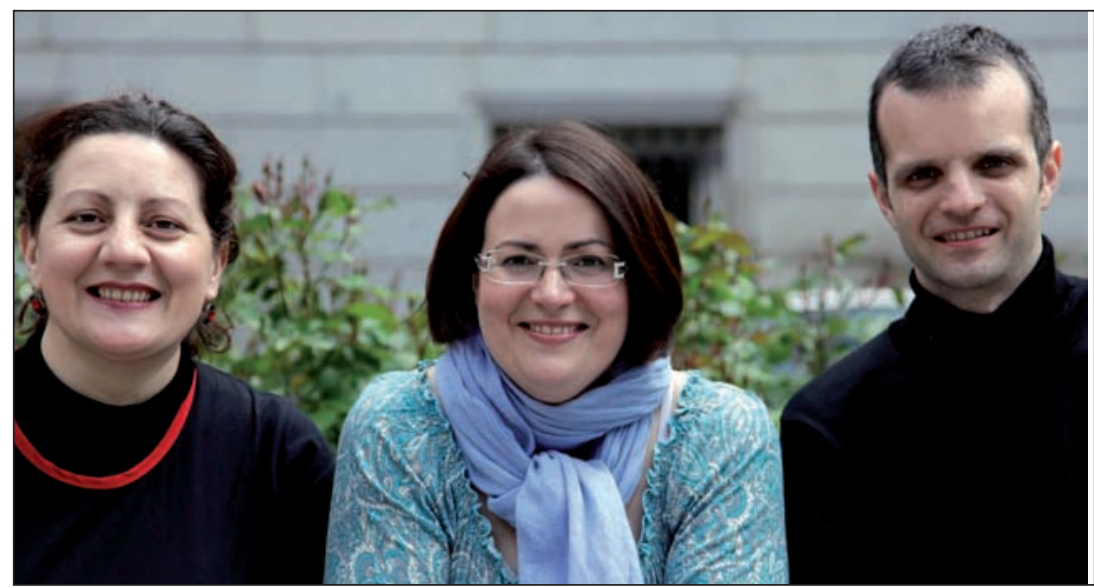

Yolanda De-la-Iglesia-Sánchez es licenciada en historia del arte por la Universidad Autónoma de Madrid (UAM) y en documentación por la Universidad de Alcalá de Henares (UAH). Es documentalista en el Departamento de Bibliotecas y Documentación del Instituto Cervantes y profesora asociada en la Facultad de Documentación de la Universidad de Alcalá de Henares.

Departamento de Bibliotecas y Documentación Dirección de Cultura. Instituto Cervantes Alcalá, 49, 2ª planta. 28014 Madrid http://www.bibliotecas.cervantes.es yolandai@cervantes.es

Pilar Uguina-Cocostegüe es diplomada en biblioteconomía y documentación por la Universidad Carlos III de Madrid (UC3M) y documentalista en el Departamento de Bibliotecas y Documentación del Instituto Cervantes.

Departamento de Bibliotecas y Documentación. Dirección de Cultura. Instituto Cervantes Alcalá, 49, 2a planta. 28014 Madrid http://www.bibliotecas.cervantes.es biblio11@cervantes.es

José-Manuel Fuertes-Conde es licenciado en comunicación audiovisual y diplomado en biblioteconomía y documentación por la Universidad Complutense de Madrid (UCM). Es documentalista en el Departamento de Bibliotecas y Documentación del Instituto Cervantes.

Departamento de Bibliotecas y Documentación. Dirección de Cultura. Instituto Cervantes Alcalá, 49, 2a planta. 28014 Madrid http://www.bibliotecas.cervantes.es biblio7@cervantes.es

\section{Resumen}

Se presentan las medidas adoptadas para adecuar la aplicación ContentDm a los requerimientos de validación de usuarios y colecciones en el proyecto de creación del banco de imágenes del Instituto Cervantes. Se exponen las características generales del proyecto, se sintetizan los objetivos y estrategias para implementar, de forma paralela, un gestor documental de uso interno que satisfaga las demandas del personal de la corporación y la difusión de las imágenes en la web. Finalmente, se apuntan las propuestas que se han llevado a la práctica para adaptar las necesidades de los usuarios a las características del gestor de colecciones digitales.

\section{Palabras clave}

Imagen digital, Bases de datos de imágenes, Software de gestión de colecciones digitales, ContentDm, Perfiles de usuario, Permisos de usuario, Restricciones de usuario.

\section{Title: Adapting the ContentDm digital collection manager to a corporate environment}

\begin{abstract}
The measures taken to adapt the ContentDm application to users' validation requirements are introduced, along with the collections in the Instituto Cervantes image bank creation project. The project's general characteristics are then laid out in a presentation. This is followed by a summary of the objectives and strategies inherent within the complex task of implementing a document manager which is suitable for both internal use to meet the needs of an institution's personnel and for the publishing of images on the internet. Finally, there is an account of the suggestions which have been put into practice to further tailor users' needs to the digital collection manager's characteristics.
\end{abstract}




\section{Keywords}

Digital image, Image databases, Digital collection management software, ContentDm, User profiles, User permissions, User restrictions.

De-la-Iglesia-Sánchez, Yolanda; Uguina-Cocostegüe, Pilar; Fuertes-Conde, José-Manuel. “Adaptación del gestor de colecciones digitales ContentDm en un entorno corporativo". El profesional de la información, 2011, noviembre-diciembre, v. 20, n. 6, pp. 689-693.

http://dx.doi.org/10.3145/epi.2011.nov.14

\section{Introducción}

La sociedad de la información se ha volcado desde hace varios años en la generación de contenidos en formatos y soportes digitales, creando todo un universo digital. Éste se ha visto favorecido por la evolución e implantación de tecnologías que responden a las nuevas necesidades de tratamiento, difusión y recuperación de información.

En el universo digital encontramos un caudal de información textual, que es el que ha tenido hasta ahora un mayor recorrido por razones obvias, pero al que le ha salido una competencia ya muy importante, el audiovisual.

El despliegue de herramientas específicas para el tratamiento de imágenes, y el uso de estándares y sistemas de recuperación en un entorno web común, constituyen los elementos para llevar a término iniciativas de mayor o menor envergadura que alimenten el acervo mundial audiovisual.

Las iniciativas y los casos de éxito son numerosos; no en vano la preferencia por la información audiovisual en nuestra sociedad es un hecho constatado. Sin embargo, a pesar de que el punto de partida es favorable, el desafío sigue existiendo porque la comunicación visual tiene sus propias fórmulas. La imagen puede tener diferentes connotaciones para el emisor y el receptor, de ahí la complicación en su análisis, descripción, distribución y uso.

Este trabajo es un ejemplo más de contribución a ese acervo mundial, que se concreta en la creación de una base de datos de acceso a la documentación digital del Instituto Cervantes (IC). El objetivo es atender la creciente demanda de documentos digitales -vídeo, texto, sonido y fotografía-, que precisa la organización, y ofrecer en abierto aquellos documentos que den a conocer la actividad de la entidad desde su creación, en coincidencia con la acción cultural en el exterior.

Para llevar a cabo este proyecto se ha utilizado la aplicación informática para la gestión de colecciones digitales ContentDm, comenzando por el tratamiento de los materiales fotográficos procedentes de la actividad del IC, que se encuentran en soporte tradicional (papel) y en soporte digital.

Se describe una parte básica del proyecto, la disposición de los diferentes niveles de restricción en la consulta y el uso de los documentos generados y almacenados en la sede y en los centros del IC. El texto está compuesto por dos partes, un análisis de la experiencia centrado en la búsqueda de alternativas de regulación del acceso a los documentos, y las conclusiones obtenidas a partir de las respuestas encontradas en la aplicación ContentDm.

\section{Objetivos y estrategias}

El estudio realizado sobre la situación de las imágenes en el IC denota un estado de "caos controlado". Caos porque es imposible tener una idea previa del número de documentos a tratar y controlado porque los depósitos de fondos digitales están localizados. Se hace necesario un sistema de preservación y recuperación de los documentos que se encuentran dispersos, casi inaccesibles y sin procesar, en la sede y en los centros.

A iniciativa del Departamento de Bibliotecas y Documentación, y concebido como un mecanismo transversal que requiere de la participación de todas las áreas de la sede y de los más de 60 centros en el extranjero, y en coordinación con los departamentos de informática, se puso en marcha la administración del activo audiovisual del Instituto para permitir una mayor y mejor difusión de las imágenes de la entidad.

El proyecto se ha diseñado según un plan de desarrollo global compuesto de tres bloques:

- Proyecto de gestión documental: creación de instrumentos de uso y control de la información a través de medios de transmisión electrónica, así como la utilización de diversas aplicaciones informáticas específicas para facilitar la vinculación entre los documentos textuales y los objetos digitales, y realizar una gestión segura y consistente del almacenamiento de los ficheros.

- Proceso de digitalización destinado a la conversión de los documentos en soporte tradicional a digital.

- Diseño de un sistema de recuperación y visualización de la información sustentado por una interfaz de búsqueda y de presentación de la información contenida en la base de datos adaptada a un amplio espectro de usuarios.

Las prioridades en el tratamiento de los materiales se han establecido por tipos documentales, y el primero ha sido la fotografía en soporte digital

Desde el principio los objetivos fueron:

- dar acceso a los materiales audiovisuales del IC;

- aportar una plataforma de trabajo actualizada y con contenidos, por medio del análisis conceptual de los materiales;

- recopilar todos los materiales existentes (patrimonio institucional), para llevar a cabo una difusión amplia y eficaz;

- integrar los archivos del IC en otros repositorios digitales. 


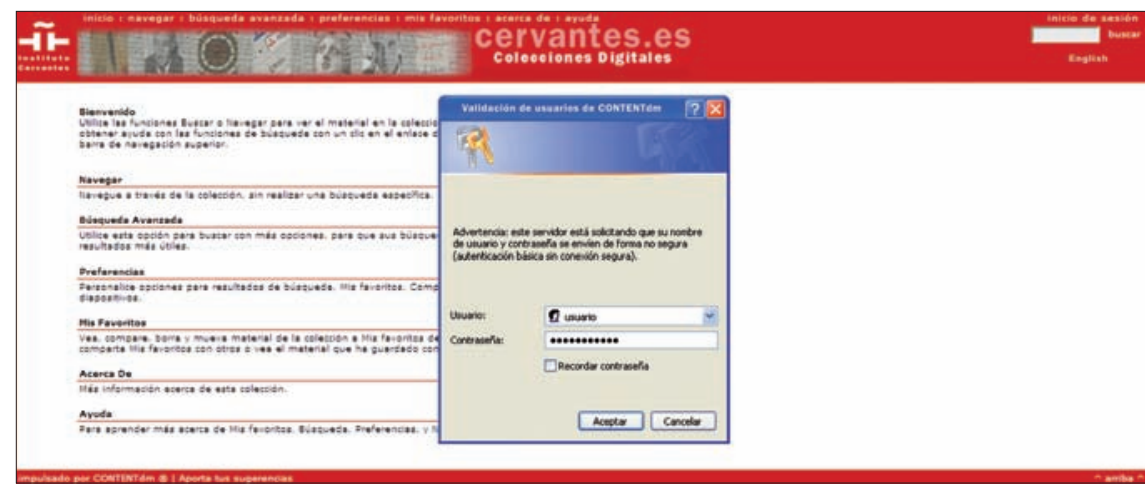

Pantalla de validación en el directorio activo del Instituto Cervantes

El software adquirido para la difusión en internet de las colecciones digitales según los estándares actuales de intercambio de información, ContentDm, permite recopilar, organizar y dar acceso web a los documentos digitales.

Las prioridades en el tratamiento de los materiales se han establecido por tipos documentales, y el primero ha sido la fotografía en soporte digital. Los documentos en este soporte son más numerosos, existe un mayor número de unidades productoras. A esto se añade que estas unidades tienen un peso específico corporativo, entre departamentos y de interacción en la sede y con los centros en el exterior.

Para la puesta en marcha del proyecto se normalizó una serie de cometidos como la recopilación y selección de los contenidos, y el análisis y diseño de una interfaz de búsqueda con la aplicación. Si bien el asunto vertebral ha sido la restricción de usuarios, el dispositivo de tareas es más extenso y en muchas ocasiones coincide con otras experiencias en la creación de bancos de imágenes. Queremos destacar el énfasis puesto en las labores de control del vocabulario y en la estructura del modelo de datos donde se ha utilizado el estándar de metadatos Dublin Core cualificado, útil para el tratamiento de una amplia gama de recursos electrónicos. La creación de los términos para la descripción de las fotografías la realizan los analistas a partir de listas precoordinadas de palabras clave y normas de redacción de las nuevas entradas. Desde el módulo de administrador del programa informático se lleva a cabo la edición, aprobación e indización de los descriptores a posteriori.

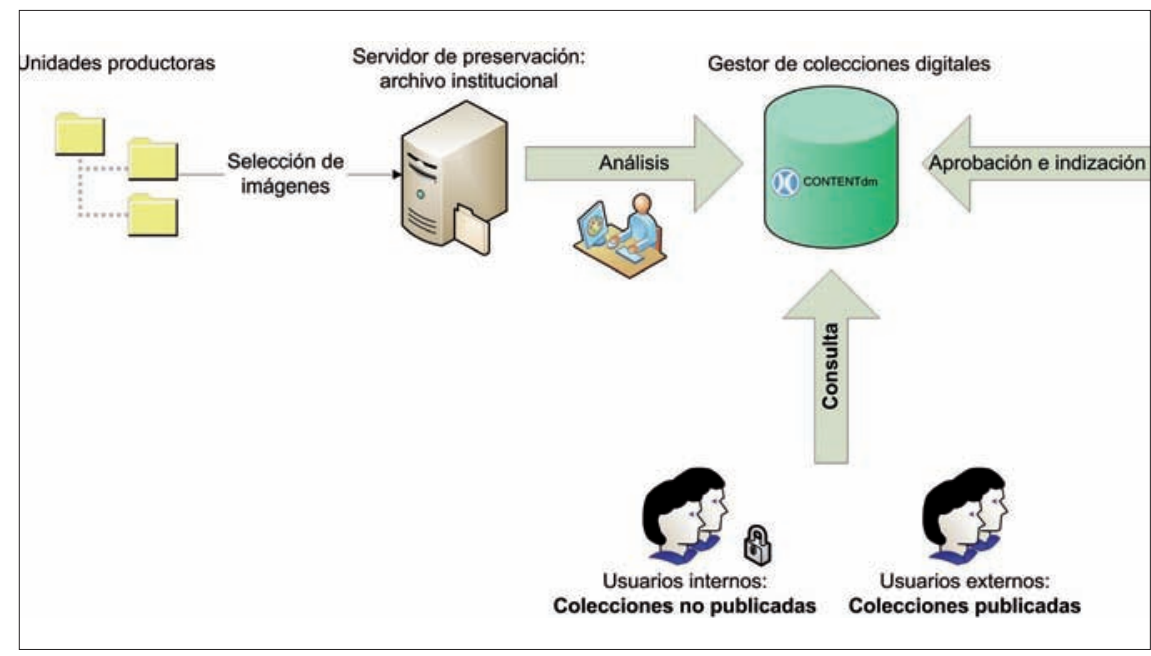

Presentación de las colecciones digitales del Instituto Cervantes

\subsection{Tipos de usuarios}

Las imágenes digitales tienen dos destinatarios finales: los usuarios internos, miembros de la organización; y los externos, con una variedad de propósitos que oscila entre el mero conocimiento de las imágenes del organismo y la reproducción en su caso.

Hay diferencias en las necesidades de información y en las limitaciones en la consulta del primer grupo, que presenta la siguiente casuística:

- Personal de actividades culturales del IC, que precisa de documentos audiovisuales para ilustrar la gestión cultural.

- Personal bibliotecario, para atender demandas específicas de documentación gráfica y para la confección de productos de información.

- Personal de gabinete y prensa, para cubrir la producción de los materiales de difusión del Instituto y para conocer y estudiar la actividad realizada a lo largo del tiempo.

- Personal docente, como apoyo para la elaboración de los materiales didácticos.

- Personal administrativo, para conocer y gestionar los bienes y obras de infraestructura de la organización.

El ajuste entre las características de un programa informático, concebido exclusivamente para la difusión pública de los documentos en la Web, y las distintas necesidades de los usuarios para acotar el acceso, ha sido el tour de force en el diseño de la colección digital en ContentDm.

Las imágenes tienen dos destinatarios: los internos, miembros de la organización; y los externos, con una variedad de propósitos

\subsection{Restricciones}

Como mecanismo de restricción en el acceso a los documentos se recurrió a las opciones disponibles en el módulo de administración de ContentDm, por medio de las cuales se modifican los detalles, el entorno (conversión a pdf, visionado de las imágenes, gestión del almacenamiento de los ficheros, derechos de las imágenes, y otros), la descripción y el estado de las colecciones.

El estado de las colecciones es un concepto esencial, que consiste en dirimir la disponibilidad de los documentos para aparecer en interfaces web públicas o restringidas. Esto se concreta en la división de las colecciones en publicadas (disponibles en la web de consulta pública) y no publicadas (no disponibles para consulta pública). 
Los miembros de la organización acceden como usuarios internos, pero con dos grados de restricción:

- Primer grado: acceso a los documentos comunes fruto de la intersección de los materiales de todas las unidades productoras, más los items señalados por cada unidad como documentos de exclusiva consulta para esa unidad productora.

- Segundo grado: acceso a los documentos comunes procedentes de todas las unidades productoras.

Por su parte, los usuarios externos visualizan la colección de imágenes seleccionadas en sus búsquedas sin necesidad de registrarse. Son colecciones públicas y no hay excepciones de ningún tipo.

\subsection{Soluciones}

El programa contempla diversas restricciones aplicables a documentos y colecciones. En ambos casos se restringe por dirección IP o por clave de usuario a través del directorio activo de la organización, el LDAP (lightweight directory access protocol). Las dificultades surgieron al tratar de compatibilizar los requerimientos de consulta de los usuarios internos con las prestaciones para la restricción en el programa.

Se inició un período de estudio y búsqueda de alternativas dentro de la aplicación ContentDm y se encontraron varias posibilidades que nuevamente fueron objeto de exploración hasta determinar la conveniencia definitiva de una de ellas.

Las soluciones manejadas fueron las siguientes:

- Interfaz de consulta limitada a la intranet. Es una opción apropiada para aquellas colecciones que sólo quieren ser gestionadas a nivel interno sin las restricciones del primer grado y la necesidad de su difusión pública. ContentDm ofrece la posibilidad de que las colecciones estén publicadas, destinadas a la web pública, o no publicadas. Si la colección está publicada y se configura el servidor para que sólo sea visible a través de la intranet, cumpliría perfectamente su cometido, pero insistimos, la colección no podría ser visible para el público externo.

- Restricción por direccción IP (internet protocol). Se tendría una colección publicada cuyos destinatarios serían los usuarios externos, y por

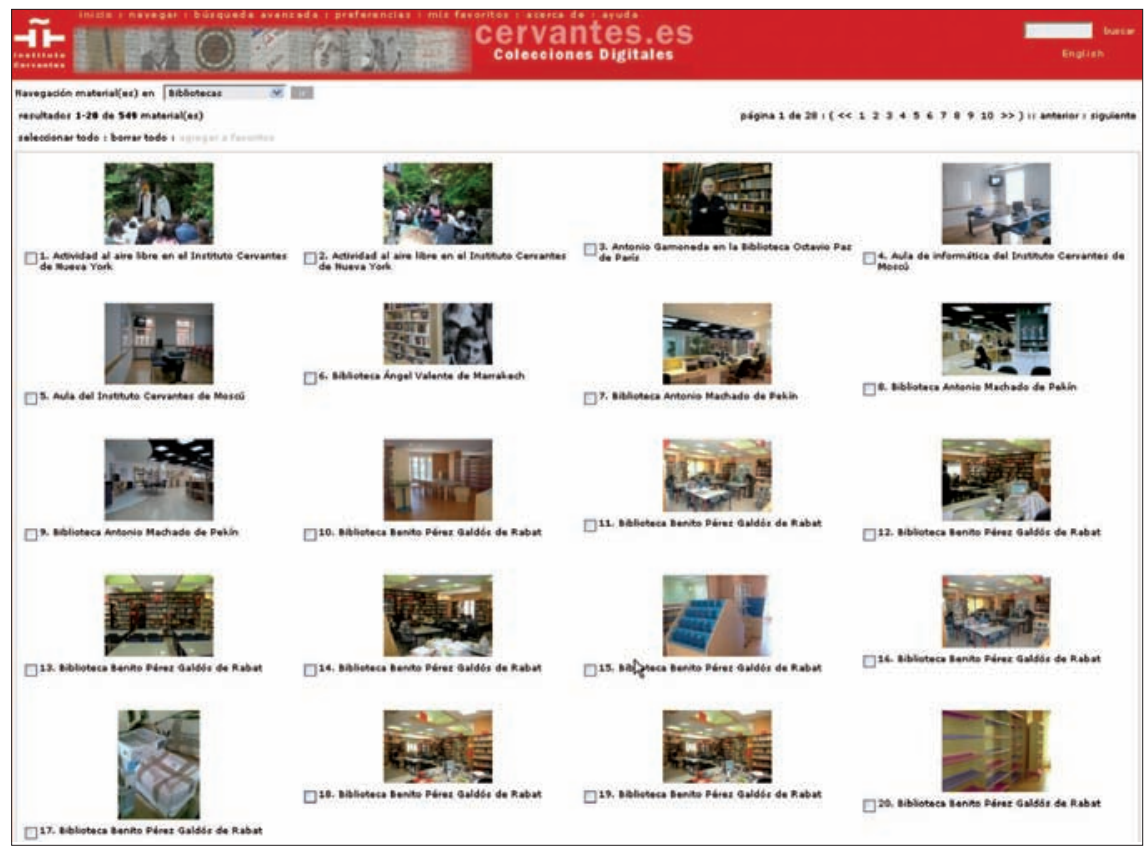

Navegación en la colección
Se ha presentado una doble necesidad en la gestión de las imágenes en el $I C$ : la pública y la corporativa

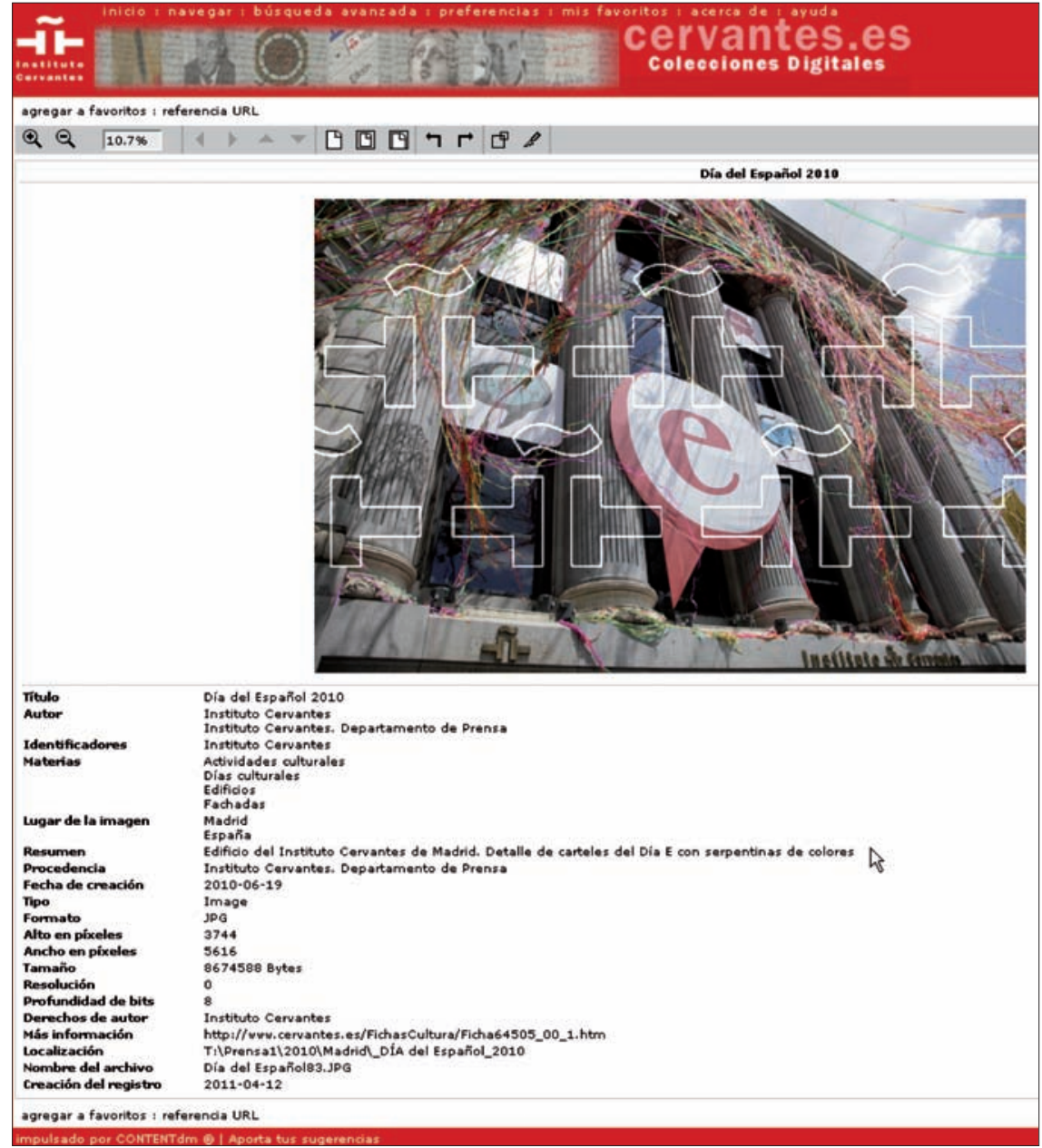

Presentación de resultados 
otro lado una colección no publicada a la que acceden mediante el reconocimiento por IP las diferentes unidades productoras. Además se introduciría una segunda restricción en algunas imágenes, también mediante IP, para que sólo puedan ser visualizadas por la unidad productora de esa imagen.

- Restricción por usuario. Es el mismo caso anterior en cuanto a las colecciones, pero se restringiría sólo por usuario. Esto implica la intervención previa del administrador en los perfiles para dar de alta a los usuarios de las unidades productoras en el ContentDm.

Las limitaciones por IP y por usuario son combinables con el estado de las colecciones.

La opción más conveniente y ajustada a nuestro proyecto es la restricción por usuario, según las características de éstos y los requisitos técnicos de los servidores y protocolos de comunicación, como por ejemplo el hecho de que las direcciones IP son dinámicas, es decir que es diferente en cada conexión.

\section{A modo de conclusión}

ContentDm, un software pensado para la difusión a través de la Web de material digital también proporciona utilidades que sirven para distintos propósitos según las particularidades de una organización.

En este artículo no se ha reseñado de manera exhaustiva el proyecto del $I C$, que, por otra parte, sigue en marcha y abierto a mejoras que llegarán con la sucesiva explotación del sistema. Tanto es así, que el estudio detallado sobre la aplicación, en los aspectos referidos en este texto, continúa, aunque se haya adoptado la restricción por usuario como solución.

Otros entornos corporativos podrían emplear una variante dentro de la restricción por usuario que consistiría en tener publicadas todas las colecciones y acotar cada una de ellas por usuario registrado en ContentDm y, a su vez, reservar aquellos documentos que la unidad productora no quiere que estén disponibles para las demás.

Se ha presentado una doble necesidad en la gestión de las imágenes en el $I C$ : la pública y la corporativa, esta última con diversas restricciones en el acceso. Estas necesidades han podido solventarse con un software de colecciones digitales.

\section{Bibliografía}

Myung-Ja Han; Bair, Sheila; Lee, Jason. "Creating metadata best practices for ContentDm users". En: Procs of the intl conf on dublin core and metadata applications: DC-2010, Pittsburgh, Pennsylvania, October 20-22, 2010, pp. 74-78. http://www.ideals.illinois.edu/bitstream/handle/2142/ 17400/HanBairLee.pdf?sequence $=2$

Dickson, Maggie. "ContentDm digital collection management software and end-user efficacy". Journal of web librarianship, 2008, v. 2, n. 2-3, pp. 339-379.

Kelly, John C. "Creating an institutional repository at a challenged institution". OCLC systems and services, 2007, v. 23, n. 2, pp. 142-147.

Zick, Greg. "Digital collections: history and perspectives". Journal of library administration, 2009, v. 49, n. 7, pp. 687-693.

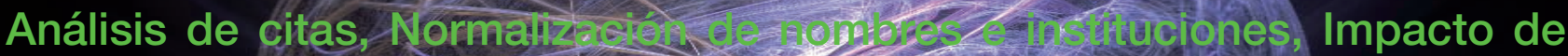

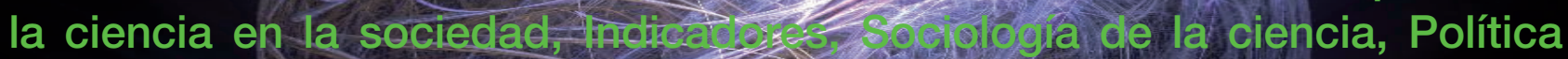
científica, Comunicación de les o o ncie Revistas, Bases de datos, Índices de impacto, Politicas de open ccess, A hial sis de la nueva economía, Mujer y ciencia, etc.

\section{Entonces INGYT es tu lista. Suscríbete en:}

